\title{
La recreación de la experiencia del instante en Viaje a la Alcarria de Cela
}

\author{
Recriando a experiência do momento em Viaje a la Alcarria de Cela
}

The Recreation of the Experience of the Instant in Cela's Viaje a la Alcarria

\author{
Randolph D. Pope \\ University of Virginia - Vírginia - Estados Unidos da América
} $\diamond$

Resumen: ¿Por qué preferir el Viaje a la Alcarria sobre otras obras de Cela? A pesar de que se inscribe en una amplia tradición de libros de viajes, la variedad y discrepancia de reacciones de los críticos revela su desconcertante originalidad. Al carecer de una tesis abarcadora y enfocarse en la recreación de diversos instantes deja a los lectores en libertad para alcanzar sus propias conclusiones. Como en el cuento de Perrault sobre las botas de siete leguas, al cual se hace alusión, se presenta los acontecimientos, por terribles que sean, sin moralizar. El mundo que se presenta vale por ser, no por significar. Su intensa presencia, sin embargo, se encuentra amenazada por la desaparición, por lo que el Viaje a la Alcarria es a la vez recreación y réquiem. Palabras clave: Cela; Viaje a la Alcarria; Feijoo; Perrault

Resumo: Por que, entre todas as obras de Cela, escolher o Viaje a la Alcarria? Apesar de fazer parte de uma longa tradição de livros de viagem, a variedade e a divergência de reações dos críticos revelam a sua originalidade desconcertante. A falta de uma tese abrangente e o foco na recriação de vários momentos, deixam os leitores livres para tirarem suas próprias conclusões. Como no conto de Perrault sobre as botas de sete léguas, a qual Viaje a la Alcarria faz referência, os eventos, mesmo que sejam terríveis, são apresentados sem moralizá-los. $\mathrm{O}$ mundo que apresenta-se vale pelo fato dele existir, e não significar. Sua presença intensa, no entanto, encontra-se ameaçada pelo desaparecimento, fazendo assim o Viaje a la Alcarria simultaneamente uma recreação e requiem.

Palavras-chave: Cela; Viaje a la Alcarria; Feijoo; Perrault

\begin{abstract}
Why prefer Viaje a la Alcarria over other works by Cela? In spite of its being grounded on a vast tradition of travel books, the variety and discrepancy of critics' opinions reveals its disconcerting originality. Lacking a framing thesis and focusing on recreating a diversity of instants, readers are granted the freedom to reach their own conclusions. As in Perrault's story about the seven league boots, to which Viaje a la Alcarria makes a reference, events are presented without moralizing, as terrible as they may be. The world presented finds it value in being, not in signifying. Its intense presence, though, is condemned to disappear, therefore making Viaje a la Alcarria simultaneously recreation and requiem.
\end{abstract}

Keywords: Cela; Viaje a la Alcarria; Feijoo; Perrault

Me sorprendo recordando que al entrar a una sala en la Fundación Camilo José Cela en Iria Flavia sentí en una forma concreta, intensa, el amplio impacto que la dispersión de las palabras de este escritor que ahora sería centenario han tenido en el mundo entero. Aquí estaban reunidas de regreso a casa un gran número de las traducciones, silenciosas, pero intimando un guirigay de lenguas y regiones. Son textos itinerantes que dan fe de los efectos de la creación cuando es verdadera y perdurable. Destacar uno entre ellos es injusto, pues la de Cela es una obra grande, profunda y del todo admirable. Me gusta especialmente $-y$ se trata de algo que es un placer intelectual con un deleite del paladar, algo inmediato- la riqueza de su lenguaje y la aparentemente inexhaustible 
profusión de su vocabulario. Pero si de esa sala en que todo se encuentra debiera seleccionar un libro, sería sin duda Viaje a la Alcarria y esto no deja de plantearme lo que ya Feijoo llamó la "razón del gusto".

No me deja escapar fácilmente el autor del Teatro crítico universal con una vaga afirmación de las preferencias personales que sentaría bien con los tiempos posmodernos: "Es Axioma recibido de todo el mundo, que contra gusto no hay disputa. Y yo reclamo contra este recibidísimo Axioma, pretendiendo, que cabe disputa sobre el gusto, y caben razones, que la abonen, o le disuadan" (FEIJOO, 1765, p. 408). Como para demostrar este aserto de Feijoo, no le han faltado al Viaje a la Alcarria numerosos encomios, así como también críticas negativas. Por el lado positivo y mayoritario, Bernard Barrère encuentra en el texto "una bocanada de aire puro, un olor a hierba mojada o aromática" (BARRÈRE, 1991, p.26), expresión que implica esa experiencia de lectura en que se involucra al cuerpo del lector y que me interesa destacar. Es una experiencia fundamental y certera. Ya Feijoo lo notaba bien contra quienes querían desdeñar un gusto que consideraban erróneo, equivocado, mal educado, pues "es imposible que abrace como delectable, objeto que realmente no lo sea. La razón es clara; porque si le abraza como delectable, gusta de él: si gusta de él, actual, y realmente se deleita en él; luego actual, y realmente es delectable el objeto" (FEIJOO, 1765, p. 409). Si Barrère sintió un placer que compara al aire puro y al olor de la hierba no queda sino maravillarse de su capacidad de superar el lenguaje académico y buscar una expresión poética y personal. Más adelante, sin embargo, parece recapacitar y busca expresar su opinión de manera más convencional:

El acierto de esa obrita maestra está en ese equilibrio entre la visión idealista y paradisíaca próxima a la novela rosa sin incurrir jamás en la ñoñez, y entre un ruralismo regeneracionista a la manera de Jean Gionoro de A. Machado y no incidiendo en un constructivismo agrario de tipo soviético o falangista, manteniendo el fielato entre el testimonio alusivo y la perfección de la pastoral (BARRÈRE, 1991, p. 27).

Me quedo con su primer intento, más cerca de la emoción de la lectura, vista normalmente como algo que debe ser superado y trascendido. Un volumen reciente de PMLA, de octubre del 2015, está dedicado a las emociones y a su importancia soterrada y reprimida que acaso pueda empezar a recuperarse y reconocerse. En su artículo introductorio, Katharine Ann Jensen y Miriam L. Wallace recuerdan que ya en el siglo XVII en las culturas occidentales el poder que la emoción ejerce sobre el cuerpo y la mente preocupaba a los pensadores que preferían creer que la mente era superior al cuerpo y las emociones (cf. JENSEN, 2015, p. 1255).
La primera percepción de Barrère, aguda, precisa y personal, nos transmite cómo el texto lo ha afectado, cómo ha sido percibido por su cuerpo, tal como puede hacerlo con el aire fresco o el olor de la hierba luego de la lluvia. El Viaje a la Alcarria se trata de un cuerpo en movimiento, al que le incomodan las botas, que tiene hambre, necesita dormir y a quien personas, animales, montañas, aves, insectos, le llaman la atención, lo concitan a experimentar su presencia. Pero luego surgen todos los peligros evitados, especialmente la ñoñez, que la DRAE define como dicho de una cosa sosa, de poca sustancia, añadiendo que coloquialmente se aplica a una persona sumamente apocada y de corto ingenio. Que esta posible caída se sitúe cercana a la novela rosa, normalmente asociada con lo femenino, podría sugerir que las distintas formas de anhelo idealista, ya sea utópico o de activismo político, deslucen, por un exceso de emoción sobre razón, de un equilibrio ejemplificado en la gran tradición de la pastoral. Barrère llega a la improbable afirmación de que el Viaje a la Alcarria "presenta un mundo de paz bucólica y de equilibrio natural casi rousseauniano" (BARRÈRE, 1991, p.26). Pero tendríamos entonces que olvidar las muchas escenas de brutalidad que presenciamos, al niño enfermo que llora la noche entera o al pastorcito adolescente que peca con una cabra, "con uno de los pecados más antiguos" (CELA, 2008, p. 136) en vez de tocar la zampoña. Tendríamos que ignorar, igualmente, "Una cabra atada a una cuerda dormita, rumiando, tumbada al sol, y un asnillo peludo [que] retoza coceando al aire como un loco" (CELA, 2008, p. 109). El "casi" que nos aparta de lo rousseauniano es catastrófico.

Hay un amplio acuerdo sobre el hecho de que Viaje a la Alcarria no surge de la nada, sino de un amplísimo contexto de previas narraciones de viaje, especialmente con resonancias de escritores del 98 y de algunos más cercanos a Cela como Pla. Sobre esto han escrito con gran autoridad y precisión varios críticos, especialmente David Henn, en su libro Old and New Spain, en que estudia todos los relatos de viajes escritos por Cela, y José María Pozuelo Yvancos, en "Cela y la tradición viajera del Noventa y Ocho" y, además, en lo que es sin duda la mejor introducción existente para este libro que se encuentra en la edición de Austral. Afirma convincentemente Pozuelo Yvancos:

Lo que los formalistas rusos llamaron "principio constructivo" o dominante de su composición no es otro que esta singularísima teoría orteguiana del paisaje que ha destacado la indivisibilidad del hombre y el medio y la condición perspectivística de la verdad o de la propia realidad que llamamos vida, mundo y paisaje. Sería inútil buscar en Viaje a !a Alcarria, como se ha hecho, un principio constructivo de naturaleza social (ni evasiva, ni comprometida) porque su dominante no 
es otra que una práctica perspectivística apoyada por lo demás en la teoría orteguiana de Ia vinculación de hombre y medio (POZUELO, 2008, p. 59).

Sotelo Vázquez sugiere la relación con el Viaje en autobús de Pla, del año 1942, y con los conceptos del paisaje de Unamuno y cita de él un texto muy pertinente: "Había que estudiarla [España] y hallarla geográficamente, esto es: caminándola, paso a paso; no leyéndola, página a página" (SOTELO, 2006, p. 11). Pero en Cela estamos lejos de las meditaciones andantes de Rousseau, de la insaciable (y muy admirable) curiosidad peregrina de Alexander von Humboldt, o la profusión de pensamientos que encontramos en Unamuno u Ortega. Incluso, y esto llevaría más tiempo demostrarlo, difiere de la obra viajera posterior del mismo Cela. El Viaje a la Alcarria es un relámpago deslumbrante y único.

Las reacciones, y aquí se manifiesta la emoción del encuentro entre los lectores y el texto, son especialmente diversas cuando se trata de imaginar y sopesar la aproximación del narrador, con una gama que va de compasivo a cruel, de objetivo a abiertamente subjetivo e irónico. Este es, ciertamente, mérito del texto, un recato que no ofrece mucho asidero para determinar con certeza cuál es la actitud del viajero. Carmen Conde, por ejemplo, ve una cordialidad abarcadora:

Mucho me ha impresionado en Viaje a Ia Alcarria no solo el andar, ver y revelar sobre un ancho pedazo de España-pueblo a Ia buena de Dios, sino Ia comprobación exhaustiva de Ia riqueza cordial del escritor junto a tantos pequeños seres desvalidos y pacientes, niños y animales; insectos y aves que entre nosotros se mueven. Pasa sobre ellos sus manos el autor para comunicarnos comprensión y tolerancia (CONDE, 1978, p. 147).

Es conocida la crítica de Juan Goytisolo a lo que considera una exposición estetizante que habría olvidado "pintar el hombre y el paisaje en el que el hombre nace, trabaja, pena y muere..." (GOYTISOLO, 1976, p. 276)1. No parece sino que Goytisolo, lector atentísimo si los hay, se ha saltado párrafos como este en Viaje a la Alcarria:

Por Valdenoches, los picapedreros parten la piedra. Están negros como tizones y llevan un pañuelo debajo de la gorra para empapar el sudor. Trabajan despacio, rendidamente, y se defienden los ojos con un cuadradito de tela metálica, atado con unas cintas a la nuca. No levantan la cabeza cuando pasa el carro (CELA, 2008, p. 103).

\footnotetext{
1 Aurora EGIDO observa muy atinadamente que a pesar de esta crítica "Los Campos [de Nijar] son, en realidad, un negativo de El viaje a La Alcarria, que se ejemplifica en la utilización de materiales idénticos con fines distintos" (151).
}

No hay ningún comentario, ni introductorio ni a continuación de esta escena que bien pudiera estar pintada por Goya. Es como si estos hombres ennegrecidos y rendidos han causado un cortocircuito del proceso narrativo. Presentarlos quema y se pasa a otra cosa. Creo que es necesario tomar en serio una afirmación que Cela hace en su "Nota a la segunda edición":

En esto de los Iibros de viajes, Ia fantasía, Ia interpretación de los pueblos y de los hombres, el folklore, etc., no son más que zarandajas para no ir al grano. Lo mejor, según pienso, es ir un poco al toro por los cuernos y decir 'aquí hay una casa, o un árbol, o un perro moribundo', sin pararse a ver si Ia casa es de este o del otro estilo, si el árbol conviene a Ia economía del país o no y si el perro hubiera podido vivir más años de haber sido vacunado a tiempo contra el moquillo. En los Iibros de viajes suele sobrar Ia pedantería.. (CELA, 1965, p. 511).

Esta escritura monda de comentario y moraleja es refractaria a la función social de aquel entonces - los años en que se escribió- y la función moral de la literatura el día de hoy. ¿No hay en este libro colonialismo interior, cuestiones genéricas, privilegios de clase y económicos que se puedan denunciar? Sin duda pueden encontrarse, pero creo que Pozuelo Yvancos acierta cuando afirma que el viajero revela una "renuncia consciente y explícita a construir una atalaya uniforme y totalizadora que significara la reducción de todas ellas a una tesis" (POZUELO, 2008, p. 25). Es el desmoronamiento de la narrativa y la continuidad, mientras se privilegia la pura aparición y presencia.

Compasivo para Carmen Conde, estetizante y por ende parcial para Goytisolo, libre de tesis para Pozuelo Yvancos, la crítica más dura viene de José María Ridao, en "El carnaval portátil de Camilo José Cela." Si estamos buscando respuestas emotivas, aquí encontramos una de alta tensión: "con la perspectiva de medio siglo, la descripción de La Alcarria realizada por Camilo José Cela produce a la vez estupor e indignación" pues encuentra una "carga de profundo desafecto humano" y "la despiadada jibarización de cuanto observa" (RIDAO, 2003, p. 57). Lo que reclama Ridao es al menos "una sola reflexión" o "apenas alguna muestra de velada piedad". No podría haber mejor ejemplo de la importancia que debemos concederle a la emoción con que nos acercamos a la lectura, pues donde la gran mayoría de los lectores ha visto una clara ternura y compasión, pero contenida, Ridao ve que "los personajes que desfilan a lo largo de sus páginas son irremediable y sistemáticamente degradados, reducidos a una condición ridícula y animal". No creo, por supuesto, que "la mirada que arrojó Cela sobre estas aldeas y sus gentes estaba cargada de una 
soberbia irrepetible" (59), como lo siente Ridao, pero creo entender que una persona generosa pueda resentir el pedernal de este texto que sigue manteniendo su fuerza de provocación. Con razón anota Pozuelo-Yvancos que "la significación del Viaje a la Alcarria, en cuanto a su contenido histórico y valor de crítica social, es muy contradictoria" (POZUELO, 2008, p. 52). Poniéndolo de otra manera, las formas en que se explica este libro son muy diversas y adquiere para distintos lectores una carga emotiva muy diferente. Robert Kirsner, en la esquina opuesta de Ridao, encontró en "La España de Viaje a La Alcarria" nada menos que la noble entereza de la España eterna... (cf. KIRSNER, 1990, p. 43).

La variedad de lecturas se debe en parte a la resistente opacidad que produce la distancia que el narrador mantiene con la experiencia que narra. El texto fue cuidadosamente escrito de regreso a casa, revisando las notas tomadas en una libreta de viaje y con la ayuda de las fotografías que tomó Karl Wlasak, quien acompañó al viajero por parte del viaje. $^{2} \quad$ Las dos líneas al final establecen lo fundamental de esta cronología distanciadora:

En el camino, del 6 al 15 de junio de 1946.

En Madrid, 16, 17, 20, 22 y 26 de junio de 1946, y 25 a 31 de diciembre de 1947 .

Estas son alertas a quien pudiera creer en la total inmediatez y espontaneidad del relato, siendo en cambio ostentaciones de una alquimia meticulosa. Ya destacó bien Charles Aubrun que Cela relegó "el petulante 'yo' a la tercera persona; y se dice: el viajero hace esto o aquello, el viajero anda, come, duerme, bebe" (AUBRUN, 1978, p.165). La distancia nos impide poder hacer juicios que puedan asegurarse como exactos sobre la interioridad del viajero y así el texto se repliega sobre sí mismo, resiste la unívoca explicación. Aubrun quizás extrema cuando afirma a continuación: "Como el mismo CervantesBenengeli en el Quijote, o como Brecht, C. J. Cela usa de Ia distanciación, colocándose en tercera persona, porque es condición imprescindible del arte" (1978, p. 166). Ciertamente puede haber arte en primera persona, pero importa aquí la reticencia a la entrega de la interioridad que tanto el viajero como Aubrun comparten y que nos abre la puerta a un aspecto notable de este texto singular: el ser así, sin más.

Pero antes de explorar este asunto, nada fácil por ir en contra de nuestra necesidad académica de explicarlo todo, quisiera fijarme brevemente en las botas. En la primera portada que Cela imaginó para su libro, escribió

\footnotetext{
2 Para la creación del texto pueden verse las detallas descripciones de Adolfo SOTELO VÁZQUEZ en "Viaje a la Alcarria: Génesis y recepción" y la Guía del Viaje a la Alcarria, de Francisco GARCÍA MARQUINA.
}

con grandes letras, primero en lápiz y luego repasado a tinta, su propio nombre y debajo "LAS BOTAS DE SIETE LEGUAS” (GARCÍA MARQUINA, 1993, p. 23). Esta referencia al cuento de Charles Perrault nos conecta con otro mundo en que se presentan escuetamente y sin aspavientos los hechos más tremendos: Un padre y una madre agobiados por la pobreza y el hambre concluyen que la mejor solución es abandonar a sus siete hijos en medio del bosque, donde seguramente encontrarán la muerte, y lo hacen no una vez, sino dos. Un niño sagaz, el menor y diminuto, Pulgarcito, encuentra el camino de regreso a casa, también dos veces, pero antes lleva a sus hermanos a la casa de un ogro cuya dieta consiste en niños frescos. Pulgarcito cambia durante la noche las coronas que llevan las hijas del ogro por los gorros que llevan él y sus hermanos, confundiendo así al ogro que tranquilamente degüella durante la noche a sus propias hijas, creyendo que prepara su cena del día siguiente. Finalmente, Pulgarcito conseguirá robarle las botas mágicas al ogro, además de toda su fortuna (engañando a su mujer), y termina de redondear su fortuna sirviendo de correo en la corte entre amantes ilícitos. El mundo es así, parece decir Perrault, y ahora, niños, dormid y tened sueños felices. Las botas de Cela, como las del ogro, no circulan por un mundo ideal, sino por uno donde el hambre tiene una presencia fantasmal, la crueldad queda sin castigo y algunos niños son devorados por la enfermedad y la ignorancia.

Hay que notar también que las botas con que el viajero comienza su viaje no parecen haber sido usadas en viajes anteriores hasta llegar a tener esa amable y benevolente adecuación al pie que tiene el calzado viejo y que por ello se valora y conserva. Habla sobre este asunto con un compañero de viaje en el tren cuando comienza su excursión:
Al viajero le vienen doliendo los pies desde que salió de Madrid. Las botas nuevas es lo que tienen, que a veces hacen daño y crían ampollitas. Revuelve en el morral y saca otro par de botas, un par de botas de lona con suela de cáñamo.
- Parece que lleva malos los pies.
- Sí, algo.
- Es natural: las botas nuevas (CELA, 2008, p. 89).

Es un caso de ambición desmedida y un indicio más de que este viaje utiliza el camino como un interludio visitando otra vida, más cercano al turismo que al montañismo, y ciertamente diferente de la vida cotidiana de quienes deben caminar porque ese es su único medio posible de movilización en su trabajo diario. En su muy recomendable libro sobre este tema, On Foot: A History of Walking, Joseph A. Amato hace un apropiado encomio de las virtudes de caminar a campo traviesa: 
Walking establishes intimate contact with place. It attaches us to a landscape-its trees, rocks, hills, and riverbanks. It makes us in good measure the streets and paths we walk. It puts us in contact with local communities. Walking coagulates time, expands distance, and makes places dense and prickly with details and complexities. It expands and defends localities against the reductionism and systematization of roads, commerce, government, and mass culture. It makes the case for individual localities in an era of rampant globalism (AMATO, 2004, p. 276).

Pero en su detallada historia de esta actividad a lo largo de los siglos, Amato nota que en los últimos dos siglos para la mayor parte de la gente caminar ha pasado de ser una necesidad a ser una opción. Las botas nuevas del viajero dejan ver que se trata de una actividad ocasional y no muy arraigada en su propia experiencia. Cuando hacia el final del relato el viajero va en coche a Zorita, nota el placer que siente por la veloz comodidad, una forma de traición de la imagen rústica que había ido creando en las páginas anteriores: "La excursión a Zorita es breve y deleitosa. Al viajero se le hace extraño viajar descansadamente y con rapidez" (CELA, 2008, p. 242). En este aspecto ha adquirido Viaje a la Alcarria un matiz nostálgico en una época en que, como afirma Amato, nuestra civilización ha disminuido considerablemente su dependencia en el viaje a pie que solía anclar la humanidad a un paisaje (cf. AMATO, 2004, p. 269). Saltamos el espacio electrónicamente, nuestra bota de las siete leguas contemporánea, y es posible recorrer virtualmente los lugares que visitó Cela el año 1946. Más corrosivamente, "the assumption that riding is a valid substitute for walking pervades the contemporary world" (AMATO, 2004, p. 270). De hecho, cuando Cela vuelve a hacer el mismo recorrido, lo hará en automóvil y con una mujer chófer, sin necesidad de botas de ningún tipo. Leyéndolo hoy, Viaje a la Alcarria puede tener una cierta impresión de réquiem. No sólo han desaparecido las personas que fugazmente transmigraron a la literatura como fotografías en blanco y negro o anécdotas escritas, sino que parte de la naturaleza que se describe ha desaparecido. Anota García Marquina lo siguiente:

El viaje a la Alcarria tiene valor de documento ecológico por sus descripciones del medio natural, singularmente en el caso de aquellas especies cada vez más alejadas, menos numerosas o incluso extinguidas. Este sería el caso del olmo, una especie frondosa muy característica en Castilla y que prácticamente ha desaparecido por una epidemia de Grafiosis (1993, p. 116).

Esta fragilidad de un paisaje que se va transformando se apunta en varias ocasiones en Viaje a la Alcarria. "Desde Pareja a Casasana no hay carretera ni camino vecinal y hay que subir el fuerte repecho por un sendero de cabras, a veces casi borrado" (CELA, 2008, p. 198). Más adelante, "En Sacedón se mete el viajero por el atajo del camposanto, camino que pronto desaparecerá bajo las aguas de un canal ya empezado a construir" (CELA, 2008, p. 210), y más ominoso:

La gente habla de los pantanos que están haciendo en el Tajo y en el Guadiela. Según aseguran, van a ser algo muy importante. Al salir de Sacedón se ve la sierra de San Cristóbal, de color verde oscuro y no muy alta. Un pastor cuida de sus cabras en un terreno que las aguas se tragarán. Al pie de la sierra han levantado unas fábricas de cemento, destinadas a surtir el pantano.

El viajero, de haber ido a pie, hubiera podido cruzar por el atajo de la Entrepeña, que también desaparecerá bajo las aguas (CELA, 2008, p. 222).

Pero el viajero ya no va a pie, sino en autobús. La imagen del pastor y sus cabras a la espera de ser anegados por el agua y el tiempo resulta emblemática de todo lo que se va quedando atrás.

El excurso a las botas y este emblema de un naufragio nos devuelve a algo que he llamado antes el ser así, sin más. No hay comentarios del viajero, sino simplemente (supuesta) percepción y entrega. Pero no son débiles viñetas anodinas, sino presencias interrogantes, una y otra vez. Ahí están, en plenitud de ser. Al comienzo del viaje, todavía en Madrid, intenta primero clasificar las casas que ve pero termina reconociendo lo improcedente de un juicio basado en pura imaginación: "Es algo muy misterioso la cara de las casas, daría que pensar durante mucho tiempo" (CELA, 2008, p. 80). Pero esto es dar vueltas a la cabeza: "Ve muy claro todo lo que piensa, y un poco confuso, quizá todo lo que ve" (CELA, 2008, p. 80). El novelista querría encontrar un argumento, hilar tramas y estructurar comienzos y finales, todo claro en el pensamiento. Pero lo que ve e irá viendo en su camino es atomizado, fragmentario, desvinculado. Ciertamente todo tiene profundidad, dimensiones espaciales y cronológicas, pero son aspectos de las existencias ajenas no perceptibles ni para el viajero ni para los lectores. Si se hacen perceptibles es en la negación, en la intensa presencia de lo que no veremos ni sabremos, como la materia oscura que, aunque no podamos verla, debemos suponer existe y da consistencia al universo. Valga el siguiente ejemplo, también sin marco, sin explicación, una pura evidencia:

La mula, descargada del equipaje, muerde los helechos de la fuente. Pasan muy altas unas avutardas, un grupo de seis o siete. Croan las ranas, y las lagartijas, que asoman, extrañadas, por los huecos de las piedras, miran un momento y huyen veloces después (CELA, 2008, p. 167). 
Seis o siete avutardas, no cinco ni ocho, en una precisión esfumada por la rapidez del vuelo y la languidez del descanso a orillas de la fuente. Las lagartijas se sorprenden ante los visitantes, pero luego van a lo suyo, huyen y desaparecen. Y no hay más. En la Introducción, Pozuelo designó esta aproximación como una "estilística de la presencia" (POZUELO, 2008, p.31), añadiendo que "no hay generalizaciones ni abstracciones, tan solo rápidas pinceladas en sucesividad, al modo de instantáneas fotográficas" (POZUELO, 2008, p. 42). Y Winston Pertaub, en un excelente estudio, "La técnica como medio de sugestión filosófica en el "Viaje a La Alcarria", nota que se evitan las afirmaciones generales y que "uno de los atractivos de la técnica de Cela es la manera como él capta tales huidizos y únicos momentos" (PERTAUB, 1969, p. 14). Creo que aquí reside en gran parte el secreto de la amplia gama de interpretaciones, pues lo que se nos entrega es un texto precisamente sin más filosofía que la presencia y sin mayor estructura que la que fue configurando el azar del camino, depurado sin duda, reconfigurado, pero al cabo no forzado en una gran narración envolvente y dominante. El último poema antes de que acabe el texto nos dice que "Por el cielo de Pastrana/vuela el azor" (CELA, 2008, p.245). No es un azor cualquiera, pero no sabremos nunca qué lo hizo ser uno particular, digno de este "el" que insiste sobre lo innegable de su presencia única. El autor supo crear la convincente ilusión de la transparencia y este azor seguirá volando en multitud de idiomas por el cielo de Pastrana, porque sí, porque la vida es grande y no hay necesidad de explicarla. Aunque cabría añadir, también porque no, porque ya no está ese azor, porque ya no está el pastor, porque el agua ha cubierto los caminos y el autor, que tendría ahora cien años, ya no vive. Celebración y réquiem, El viaje a la Alcarria, persiste radiante y enigmático.

\section{Referencias}

AMATO, Joseph A. On Foot: A History of Walking. New York: New York UP, 2004.

AUBRUN, Charles. Guía singular del Viaje a la Alcarria, Cuadernos Hispanoamericanos, v.337-338, p. 165-173, 1978.
BARRÈRE, Bernard. De la Arcadia a la Alcarria: Idilio expiatorio o bisagra ideológica. La palabra en libertad. Homenaje a Camilo José Cela, II. Murcia: Paraninfo, 1991. p. $25-45$.

CELA, Camilo José. Viaje a la Alcarria. Introducción de José María Pozuelo Yvancos. Madrid: Austral, 2008.

CELA, Camilo José. Nota a la segunda edición. Obra Completa, Tomo IV: Viajes por España, I. Barcelona: Ediciones Destino, 1965. p. 509-512.

CONDE, Carmen. Camilo José Cela: Viaje a La Alcarria. Cuadernos Hispanoamericanos, Madrid, v. 337-338, p. 147-164, 1978.

EGIDO, Aurora. En los Campos de Nijar, de Juan Goytisolo. Cuadernos de Investigación Filológica, La Rioja, v. 5, p. 149-162, 1979.

FEIJÓO, Benito Jerónimo. Razón del gusto. Theatro [sic] crítico universal. Tomo VI. Madrid: Gabriel Ramírez, 1765. p. 408-423.

GARCÍA MARQUINA, Francisco. Guía del Viaje a la Alcarria. Guadalajara: AACHE Ediciones, 1993.

GOYISOLO, Juan. El furgón de cola. Barcelona: Seix Barral, 1976.

HENN, David. Old and New Spain: The Travel Narratives of Camilo José Cela. Madison: Fairleigh Dickinson UP, 2004.

JENSEN, Catherine, y Miriam L. Wallace. Introduction: Facing Emotions. PMLA, New York, v. 130, p. 1249-1268, oct. 2015.

KIRSNER, Robert. La España de Viaje a La Alcarria. Ínsula, Madrid, v. 45, n. 518-519, p. 42-43, 1990.

PERTAUB, Winston. La técnica como medio de sugestión filosófica en el 'Viaje a La Alcarria'. Ínsula, Madrid, n. 277, p. 14 , dic. 1969.

POZUELO YVANCOS, José María. Cela y la tradición viajera del Noventa y Ocho. Ínsula, Madrid, v. 59, n. 518/519, p. 58-59, 1990.

POZUELO YVANCOS, José María. "Introducción” a Camilo José CELA, Viaje a la Alcarria. Madrid: Austral, 2008. p. 9-55.

RIDAO, José María. El carnaval portátil de Camilo José Cela. Añil, Castilla-La Mancha, v. 25, p. 57-59, 2003.

SOTELO VÁZQUEZ, Adolfo. Viaje a la Alcarria: Génesis y recepción. El Extramundi y los Papeles de Iria Flavia, Iria Flavia, v. 12, p. 730, 2006.

Recebido: $27 / 11 / 2015$

Aprovado: 04/01/2016

Contato: rdp6g@Virginia.edu 